\title{
Teaching Theory, Writing Policy: Integrating Lessons from Foggy Bottom into the Classroom
}

Bidisha Biswas, Western Washington University

Agnieszka Paczynska, George Mason University

ABSTRACT This article describes guidelines for assignments designed to build and improve policy-oriented writing skills of college students. Based on our experiences as Franklin Fellows at the United States Department of State, we developed strategies for teaching writing skills that are transferable to the workplace. The pedagogical approaches highlighted in this article will equip students with the analytical and writing abilities needed in a variety of employment situations. First, we offer insights into the qualities that we believe are important for success in a policy-oriented work environment. Second, we link those skills to the challenges and gaps that students face. Third, we propose assignments that can address those gaps.

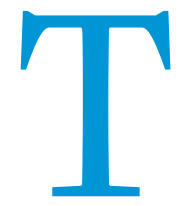
his article provides guidelines for approaches and assignments designed to build and improve policyoriented writing skills of college students. We first offer insights into the skills that are important for success in a policy-oriented work environment. We then link those skills to the challenges and gaps that students face. Finally, we propose assignments that can address those gaps. The article draws on our experiences while serving as Franklin Fellows at the United States Department of State. ${ }^{1}$ Throughout our time in Foggy Bottom, we considered the ways in which exposure to the world of foreign-policy decision making could inform our teaching.

\section{BEYOND DIPLOMACY}

Although our suggestions are based on our experiences at the State Department, we believe that the analytical skills discussed in this article will equip students in a variety of employment situations. In the United States and elsewhere, there is a growing debate about the extent to which college education enables students to improve their prospects for finding a job and to excel in the job(s) that they do find. Political science is under scrutiny for its relevance to current undergraduate students and to the policy environment in general (Curtis 2014; McMillan 2014).

Trueb (2013) points out that a majority of American political science graduates work, or seek work, in the federal government.

Bidisha Biswas is an associate professor of political science at Western Washington University. She can be reached at bidisha.biswas@wwu.edu.

Agnieszka Paczynska is an associate professor in the School for Conflict Analysis and Resolution at George Mason University. She can be reached at apaczyns@gmu.edu.
They also seek employment in international organizations; local, state, or regional bodies; and other organizations in which policybased writing is an essential requirement of the job. Since completing our fellowships, we have developed teaching strategies and assignments that build on the insights we obtained while at the State Department. The guidelines discussed below will help foster intellectual agility and develop writing skills that are transferable to the workplace.

\section{THE IMPORTANCE OF BEING A WRITER}

At the State Department, we had the opportunity to be involved in several negotiating environments with dignitaries from other countries as well as in domestic decision-making processes. We observed that the principal skill by which junior- and middle-level officers are assessed is their ability to write papers. Indeed, as we discovered, there is a good reason why bureaucrats are often termed "paper pushers." Writing and revising papers consume a significant portion of the work hours of many, if not most, officers at the State Department.

Policy papers take a variety of forms. Cables, which are submitted by officials at overseas US posts, summarize events that are unfolding in the relevant country or locale. For example, a cable from Dhaka, Bangladesh, in January 2014 might have detailed the violence that took place during the controversial parliamentary elections held that month. In the Washington, DC, offices of the State Department, most papers are written to prepare senior officials or principals for meetings or to inform them about facts and analyses that will shape policy decisions. For example, an officer might be asked to write a paper in advance of a meeting between a senior US official and a leading member of the Bangladesh 
ruling party. Such a meeting might be oriented toward US and international concerns about electoral violence in Bangladesh. In another instance, a principal might require information about debates surrounding industrial safety in Bangladesh in the aftermath of serious factory accidents in the country. This input can succession in a fast-paced and often frenetic environment. This means that writers must complete their task with alacrity and be able to juggle multiple assignments and meetings. An analysis of the Afghan elections should briefly cover key issues, expected outcomes, and risk assessments.

\section{At the State Department, we rarely saw papers that were longer than three pages. We were both told, on multiple occasions, that "only the first page matters."}

help develop or defend an official position on whether to recommend a suspension of Bangladesh's trade privileges in the United States until safety standards are improved. In a third example, a senior official might be called on by members of the US Congress to provide a briefing on State Department responses to industrial safety or electoral violence in the South Asian country. In this situation, the officer in question will need summaries of the unfolding situation and analytical explanations of US government responses.

Papers might also be written to assist in preparation for press meetings or discussions with officials from other US government departments. Beyond the State Department, employees of organizations that focus on policy issues may be asked to summarize and analyze a complex situation and present it to their work team or leaders. For example, someone working at an environmental consulting firm might be asked to discuss and evaluate the debate surrounding the controversial Keystone XL US-Canada pipeline project.

It is important, first and foremost, to understand the audience and purpose for which a paper is being written. In most situations, audience members will have certain characteristics in common. The senior officer to whom the paper is directed is typically juggling several different issues, challenges, and meetings. As a consequence, she is pressed for time. The principal will, therefore, prefer a paper that provides a comprehensive, clear, and concise analysis. At the State Department, we rarely saw papers that were longer than three pages. We were both told, on multiple occasions, that "only the first page matters." As such, the writer of a State Department paper is expected to display the following competencies:

1. Understand, respond to, and stay focused on the question(s) being asked. Although the issue being evaluated may be complex (e.g., a risk analysis of Afghanistan in the context of the 2014 presidential elections), a writer is expected to grasp the principal's specific interest. For example, is she giving a briefing to members of Congress? Is she meeting with a dignitary from Afghanistan? Or is she meeting a representative from the Pakistani government who wants to discuss the situation in Afghanistan?

2. Engage in evidence-based reporting and analysis. Writers need to base their writing on sound evaluation and analysis of available data. For example, assessments about the post-election scenario in Afghanistan must be based on a careful sifting of available information that distinguishes between objective analysis and speculation.

3. Provide quick and clear writing. Policy writing involves communicating with audiences that read several papers in rapid
Educators lament the fact that student writing often lacks essential competencies, including a clear, sustained, and evidence-based line of thought (Çavdar and Doe 2012). Students tend to neglect to follow instructions carefully as they meander through class assignments. A media environment suffused with opinion-heavy, fact-light "information" makes it difficult to separate reasoned analysis from biased or ill-formed opinions. Students should learn how to separate fact from opinion; identify source bias; and express their ideas clearly, concisely, and in ways that are tailored to audience needs. The assignments we propose should help students acquire and strengthen those competencies.

The following three goals will help to build the requisite skills of focus, evidence-based analysis, and clarity in communication:

1. Students must be able to summarize a situation in a way that is relevant to the question being asked. They should demonstrate the ability to synthesize different and often contrasting points of view to present as holistic a picture as possible. For example, in the Bangladesh situation, they must review many different variables. What types of violence have occurred? Who are the perpetrators of the violence? Who are the targets or the victims of the violence?

2. Students must be able to analyze a situation. What are the relationships between the targets and the perpetrators of the violence? Why is the violence occurring? What are the key implications for US interests in that country? What are the regional implications?

3. In the workplace, policy analysts will be expected to submit and justify recommendations on responses to the current situation. How should the US government respond to the political situation in Bangladesh? What are the alternatives and what are the pros and cons of each option?

The ability to make recommendations is honed through on-the-ground experience. However, entry-level officers in Foggy Bottom are expected to develop the necessary knowledge base and orientation quickly. We attempt to prepare students for such expectations by helping them understand the value of data evaluation and analysis as well as the process of logical argumentation and justification.

In summary, to gain the skills expected of junior policy analysts, students need the ability to engage in writing that is time-sensitive, concise, and persuasive. Logical justification and clear argumentation are essential. College students are often not adequately prepared to meet these demands. To bridge the gaps between competencies and professional expectations, focused class activities and writing assignments should be developed. The following three assignments, which can be incorporated into a variety 
of courses, illustrate some of the ways in which students can be encouraged to summarize, analyze, and create.

\section{UNDERSTANDING THE NEWS}

The first step to good writing is good research. Collating and sifting through various sources of information are essential to providing a succinct yet comprehensive summary of a given situation. This is particularly important when an issue is controversial and a plethora of opinions may be offered by available sources.

At the State Department, officers typically gather information from news sources and think-tank reports rather than peerreviewed scholarly articles. They are expected to do so with a critical and selective eye. In the information-saturated environment in which we work, gleaning sound facts and logical arguments can be challenging. Because of the sheer volume and variety of information-much of which is bundled in quick-consumption formats-students may not be able to process the available data points and arrive at a reasoned judgment based on accuracy rather than conjecture and prior biases (Çavdar and Doe 2012). To enhance their skills for the workplace, students should be able to demonstrate the ability to differentiate between analyses and opinions and to evaluate the relative strengths and weaknesses of a particular argument or position. a conflict in a Liberian town. Each packet includes newspaper articles, interviews with both town residents and international-organization representatives, and visual aids. Students are asked to analyze the data contained in their group's packet, write a brief conflict analysis, and present their findings to the class. Hearing very different analyses from each group, the students realize that each packet contained slightly varying newspaper accounts and interviews with different people. This realization invites an in-depth discussion of data gathering and evaluation. It alerts students to the potential biases of data and helps them understand how the identity and interests of the interviewees, witnesses, and writers can shape their perception and presentation of events.

\section{WHAT WOULD YOU DO?}

Policy officers are often asked to be analytical in their writing. In Foggy Bottom, as in many other jobs, writers are expected to evaluate and critique arguments made by others. They also may be asked to present and defend their office's position on a particular issue. The declining writing ability of college students and young employees is lamented by many academics and employers. A critical problem in college-level writing is that students simply regurgitate what they have read, often with the onerous aid of lengthy,

\section{To enhance their skills for the workplace, students should be able to demonstrate the ability to differentiate between analyses and opinions and to evaluate the relative strengths and weaknesses of a particular argument or position.}

In consultation with colleagues at other institutions, Biswas developed an assignment module titled "Topics in the News." This exercise builds transferable skills in summarizing. In a class on the politics of South Asia, she asks students to gather two separate news items on four or five specific topics throughout the course of the term. Examples of themes include violence against religious minorities in Bangladesh and the linkages between corruption and industrial safety in the country's apparel industry. For each topic, students must select two articles, at least one of which must be from a South Asian news source. They are required to summarize the articles and write a brief two-page analysis. The papers should reflect on the biases, if any, in the news items.

Students then present their findings in class in order to facilitate group discussion, feedback, and learning. After the first two submissions, most students show a significant improvement in their ability to assess and compare different news items. This improvement is facilitated by peer feedback, which helps students become aware that a particular event (e.g., a border skirmish between Indian and Pakistani soldiers) can involve various perspectives (e.g., contrasting reporting on which side initiated the precipitating border transgression). Over time, students show improvement in their ability to recognize points of bias and to synthesize different news items into a cohesive analysis.

In collaboration with colleagues at her institution, Paczynska developed a conflict-assessment exercise titled "Community at Odds" that draws on her experience as a participant in a US Government interagency conflict assessment in Liberia. ${ }^{2}$ Students are divided into groups and given a packet of information about direct quotes taken from the text. This directly affects a college graduate's ability to meet the demands of a policy-oriented job. Although it is not possible for college educators to provide remedies for the background conditions (e.g., barriers to developing effective writing skills in secondary school), it is possible to develop assignments and grading rubrics that encourage stronger argumentation and analytical skills (Rublee 2014). Class time should also be devoted to distinguishing between summarizing, offering unsubstantiated opinions, and justifying argumentation.

One way that we have addressed this issue has been to create written assignments centered on simulations. A substantial amount of literature already exists on the use of simulations as an important pedagogical tool (Asal 2005; Truby, Weiss, and Rousseau 2014; Wedig 2010). Simulations of foreign-policy scenarios can be a valuable tool to bridge extant learning gaps and prior biases. A recent article (McMillan 2014) provides excellent examples of encouraging critical thinking and writing skills through the use of simulations. We propose that these exercises be used to present students with a "What Would You Do (WWÝD)" challenge. We seek to place students in situations in which they must debate, defend, and/or critique a certain set of decisions that they made during the course of a simulation (Truby, Weiss, and Rousseau 2014). The ultimate goal of this exercise is to improve their analytical skills.

We have used the WWÝD challenge during a simulation of an India-Pakistan crisis that is available through the ICONS project at the University of Maryland. ${ }^{3}$ Based on a terrorist attack in Mumbai in 2008, the simulation puts the students in the roles of key actors in the aftermath of a fictional, large-scale attack on 
New Delhi that results in numerous civilian casualties. The attack is believed to have been planned in Pakistan. The teams represented in the crisis are India, the Pakistani civilian government, the Pakistani military, the United Nations, and the United States. Throughout the crisis negotiations, students obtain a keen understanding of the geopolitics of the region and ways in which state and quasi-state actors influence and are influenced by the event.

The post-simulation reflection paper-about four pages in length-is an important component of the exercise. We ask students to reflect, defend, and critique the positions and decisions taken by their team. For example, the US team may explain why it chose a more passive stance toward the conflict as events unfolded. Was it because the team became more aware of the geopolitical constraints that the US faces in the region? Did the team's tactics change due to intragroup dynamics? To what extent did a realist, liberal, constructivist, or game-theoretic framework influence their decisions? Answering these questions helps students understand structural issues in international relations as well as foreign-policy decision-making processes.

As with other writing assignments, students are required to answer complex questions in a concise format. A grading rubric that asks specific questions relating to a critical reflection of the simulation can greatly facilitate concise and focused writing.

\section{ACTION MEMO}

The action-memo assignment focuses on the third skill described previously-that is, suggesting creative solutions to a particular problem or making recommendations. Most college students have limited capacity in this area because of their relative lack of on-the-job experience. ${ }^{4}$ Our goal is to incorporate the foundational skills for making reasoned recommendations by emphasizing logical argumentation skills. This exercise is most suitable for upper-level undergraduate and graduate courses.

In this exercise, students are given a particular policy challenge and asked to choose among different action options, given limited information and time. They must justify their choice using international theories and provide supportive, logical arguments. Alternatively, they are given an article that discusses an issue of considerable policy complexity and asked to distill and invaluable skill for students of political science, whether or not they seek a career in academia. At the State Department, as in a number of think tanks, employees are expected to glean and analyze information from numerous sources. They may also be asked to engage with contradicting reporting or analyses. Students need to learn the importance of providing evidence and counterevidence when they present an argument. Therefore, a demonstrated ability to compare, contrast, and apply theoretical frameworks should be the foundational requirement of every assignment. The scientific method, which involves in-depth knowledge, logical reasoning, and provision of evidence, is an important tool for responsible policy making. 5

We suggest that grading rubrics for written assignments include the following two requirements: (1) a variety of analytical and empirical studies incorporated as supporting evidence, and (2) the students' own critiques and analyses including careful comparison and contrast of those studies. It is helpful to provide students with a diverse list of resources (e.g., think tanks and relevant journals). Students should be required to demonstrate a substantial knowledge base and rigorous, systematic analytical skills. This ability will hone their research skills while still emphasizing concise writing.

\section{CONCLUSION}

Recent articles on pedagogy in the social sciences emphasize the importance of analytical writing. Assignments that develop these skills can help meet the employment needs of students. Short papers can also be used as writing samples to accompany job and internship applications (Jaschik 2009; McMillan 2014). Furthermore, we encourage students to proactively discuss their critical thinking and writing skills in resumes, cover letters, and interviews. In a challenging job environment, a confident discussion of the writing skills they developed in college should help students of political science position themselves competitively. Craig (2014) reminds us that the scholarly endeavor focuses on clarifying concepts and facts through a process of scrutiny and critiquing. This is the essence not only of academic writing but also of policy writing. The walls between the ivory tower and the policy world may be more porous than initial appearances indicate.

\section{Students need to learn the importance of providing evidence and counterevidence when they present an argument. Therefore, a demonstrated ability to compare, contrast, and apply theoretical frameworks should be the foundational requirement of every assignment.}

explain the top two or three ideas in the article. Students should be encouraged to apply international relations theory to explain and justify their evaluation.

\section{A PLACE FOR RESEARCH}

Some of our colleagues expressed the concern that shorter papers may inadvertently disincentivize research. Indeed, because students are required to condense their summary, analysis, and recommendations to three or four pages, they might be tempted to restrict themselves to two or three pithy sources. We contend that developing strong research and methodological skills remains an

\section{ACKNOWLEDGMENTS}

The authors acknowledge the valuable input provided by Victor Asal, Sunila Kale, Ramya Vijaya, and two anonymous reviewers at PS: Political Science and Politics.

\section{NOTES}

1. The State Department's offices are located in the Foggy Bottom area of Washington, DC. In 2012-2013, Bidisha Biswas served as a policy advisor on conflict, security, and human rights issues in South Asia. In 2008-2009, Agnieszka Paczynska worked in the Office of the Coordinator for Reconstruction and Stabilization, where she served as a conflict specialist focusing on several countries, including Afghanistan and Liberia. 
2. The exercise is available at http://scar.gmu.edu/experientiallearningproject/11613.

3. See www.icons.umd.edu.

4. Nontraditional students who enter college after obtaining substantial work experience may demonstrate stronger creative abilities.

5. Studies that illustrate the relevance of the scientific approach to policy work include George and Bennett (2005).

\section{REFERENCES}

Asal, Victor. 2005. "Playing Games with International Relations" International Studies Perspectives, 6 (3): 359-373.

Çavdar, Gamze, and Sue Doe. 2012. "Learning through Writing: Teaching Critical Thinking Skills in Writing Assignments." PS: Political Science \& Politics 45 (2): 259-64.

Craig, John. 2014. "What Have We Been Writing About? Patterns and Trends in the Scholarship of Teaching and Learning in Political Science." Journal of Political Science Education 10 (1): 23-36.
Curtis, Steven. 2014. "Teaching the Practice of Diplomacy." Paper presented at the APSA Teaching and Learning Conference, Philadelphia, February 7-9, 2014

George, Alexander L., and Andrew Bennett. 2005. Case Studies and Theory Development in the Social Sciences. Cambridge, MA: MIT Press.

Jaschik, Scott. 2009. "Poli Sci Reformation." Inside Higher Ed. September 4. Available at https:/www.insidehighered.com/news/2009/09/04/polisci.

McMillan, Samuel Lucas. 2014. "Bravo for Brevity: Using Short Paper Assignments in International Relations Classes." International Studies Perspectives 15 (1): 109-20.

Rublee, Maria Rost. 2014. "Rubrics in the Political Science Classroom: Packing a Serious Analytical Punch." PS: Political Science \& Politics 47 (1): 199-203.

Truby, Katherine, Meredith L. Weiss, and David L. Rousseau. 2014. "Teaching the Unfamiliar to a Crowd." PS: Political Science \& Politics 47 (1): 189-94.

Trueb, Bettina. 2013. "Teaching Students to Write for 'Real Life': Policy Paper Writing in the Classroom.” PS: Political Science \& Politics 46 (1): 137-41.

Wedig, Timothy. 2010. "Getting the Most from Classroom Simulations: Strategies for Maximizing Learning Outcomes.” PS: Political Science \& Politics 43 (3): 547-55. 